\title{
Determination of Ursolic Acid a Biomarker in Different Swertia Species through High Performance Thin Layer Chromatography
}

\author{
Mansi Gupta, Deepa Bisht, Sayyada Khatoon, Sharad Srivastava, Ajay Kumar Singh Rawat \\ Pharmacognosy and Ethnopharmacology Division, National Botanical Research Institute (CSIR), Lucknow, India \\ E-mail:pharmacognosy1@rediffmail.com \\ Received January 21, 2011; revised February 10, 2011; accepted April 14, 2011
}

\begin{abstract}
A simple highly precise method has been established for the determination of ursolic acid in three species of Swertia viz. S. angustifolia, S. paniculata, and S. alata. The assay combines identification and quantification of the analyte on silica gel $60 \mathrm{GF}_{254}$ HPTLC plates with visualization under UV light and scanning at $510 \mathrm{~nm}$.
\end{abstract}

Keywords: Ursolic Acid, Swertia Species, HPTLC

\section{Introduction}

Swertia (family: Gentianaceae) is widely distributed throughout the temperate regions of Asia, Europe, America, Africa, and Western Himalayas at altitudes of ca. 1500 $2400 \mathrm{~m}$ from Kashmir to Nepal and China. Around 40 species of Swertia have been found in India and 15 occur in the Himalayan regions of Uttaranchal, of which, $S$. chiraita is well-known for numerous medicinal applications [1]. Several Swertia species are being used as substitutes or adulterants of $S$. chiraita and are known for their therapeutic potential against fever, hepatitis, cholecystitis, pneumonia, osteomyelitis, dysentery, scabies, spasm, pain, and malaria, and used as antidepressant, mutagenic, antipsychotic, tuberculostatic, choleretic, antioxidant, anti-inflammatory, and antidiabetic drugs [2-7].

Swertia is known as a rich source of xanthones, some species also containing terpenoids and seco-iridoids [2,3, 7]. Previous chemical investigations of the plants have revealed the presence of the Lupeol [8], Mangiferin [9, 10], $\beta$-sitosterol, 3- $\beta$-D-glucoside [11] and ursolic acid [12]. In an earlier study, 1-hydroxy-8-glucosyloxy-3, 5dimethoxyxanthone, 1, 8-dihydroxy-3, 7-dimethoxyxanthone, 3-methoxy-1, 5, 8-trihydroxyxanthone and ursolic acid have been reported from its aerial parts [7] with potent antioxidant activity [13], but there has been no report on the quantitative estimation of ursolic acid in these species.

Hence, in this study we report a simple and highly precise high-performance thin-layer chromatographic (HPTLC) method for the determination of ursolic acid (Fig- ure 1). An attempt has also been made to validate the developed method in terms of precision, repeatability, LOD, LOQ and accuracy. The method is also suitable for industrial quality control and successful commercial exploitation of these species.

\section{Experimental}

\subsection{Plant Material and Reagents}

The whole plant of three different species of Swertia viz. S. angustifolia, S. alata and S. paniculata were collected from Kalamuni (Uttarakhand, India). The specimens were authenticated and a voucher specimen of each species was deposited in the Institute's herbarium (LWG 222437SAL, LWG 222438SAG, and LWG 222439SP, respectively.

Ursolic acid was from Sigma-Aldrich (Steinheim, Germany); other reagents were from Merck (Germany).

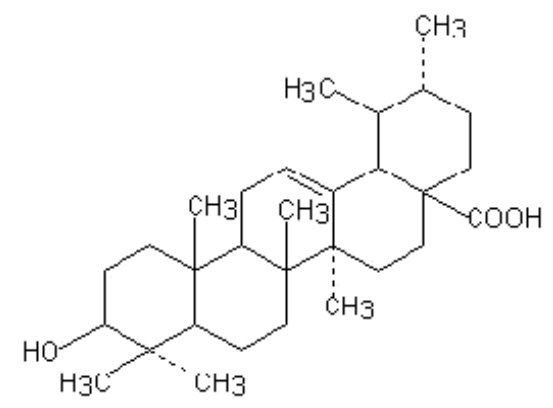

Figure 1. Structure of ursolic acid. 


\subsection{Extraction of Plant Material}

Air dried $\left(45^{\circ} \mathrm{C}-55^{\circ} \mathrm{C}\right)$ powdered whole plant of the three different Swertia species (each $2.0 \mathrm{~g}$ ) were extracted separately with $3 \times 20 \mathrm{ml}$ methanol. Extracts were evaporated to dryness under vacuum and $10 \mathrm{mg}$ of residues were re-dissolved in methanol $(1 \mathrm{ml})$.

\subsection{Standard Solution}

A stock solution $\left(0.1 \mathrm{mg} \cdot \mathrm{mL}^{-1}\right)$ of ursolic acid was prepared by dissolving $2.5 \mathrm{mg}$ ursolic acid standard, accurately weighed, in $25 \mathrm{~mL}$ methanol in volumetric flask.

\subsection{Chromatography}

HPTLC was performed on $10 \mathrm{~cm} \times 10 \mathrm{~cm}$ silica gel 60 $\mathrm{GF}_{254}$ plates (Merck). Samples and ursolic acid standard of known concentration were applied to the layers as 6 $\mathrm{mm}$-wide bands, $15 \mathrm{~mm}$ from the bottom and sides of the plates by use of a Camag Linomat 5 automated TLC applicator with the nitrogen flow providing a delivery speed of $150 \mathrm{nl} \cdot \mathrm{s}^{-1}$ from the application syringe. The plates were developed to a distance of $80 \mathrm{~mm}$ with tolueneethyl acetate-formic acid (8:2:0.1) as mobile phase in a Camag twin-trough glass chamber previously saturated with mobile phase vapor; temperature was $20^{\circ} \mathrm{C}$. After removal of plates from chamber, completely dried in air at room temperature $\left(27^{\circ} \mathrm{C}\right)$ and peak areas for samples and standard were recorded by densitometry in absorbance/reflection mode at $\lambda \max =510 \mathrm{~nm}$, by means of a Camag TLC Scanner 3 with WINCATS version 3.2.1 software.

To prepare calibration plot, stock solution $\left(0.1 \mathrm{mg} \cdot \mathrm{ml}^{-1}\right)$ of ursolic acid was prepared and different volumes of the solution were analyzed by HPTLC as described above. Calibration plots were prepared by plotting peak area against concentration.

\subsection{Method Validation}

Precision was checked by repeated scanning of the same spot of $\left(3 \mu \mathrm{g} \cdot \mathrm{spot}^{-1}\right)$ six times and results were expressed in terms of relative standard deviation (\% RSD). The repeatability of the method was done by analyzing the spots of $3 \mu \mathrm{g}$ standard solutions after application on the HPTLC plate $(n=5)$ and expressed in terms of \% RSD. Variability of the method was studied by analyzing aliquots of standard solution of $(0.4,0.8,1.6,3.2,6.4$ and $8.0 \mu \mathrm{g} \cdot \mathrm{spot}^{-1}$ ) on the same day (intra-day precision) and on different days (inter-day precision) and the results were expressed in terms of $\%$ RSD. The accuracy of the method was determined by recovery studies. Standard spiked with three different amounts of $(400,600$ and 800 ng) in plant samples were analyzed and the percent recovery calculated. Different dilutions of standard solutions in methanol were applied. Limit of detection (LOD) and limit of quantification (LOQ) were determined on the basis of signal to noise ratios of 3:1 and 10:1.

\section{Results and Discussion}

To obtain high resolution and reproducible peaks, mobile phases of different composition were investigated for HPTLC analysis. The desired profile was achieved in toluene: ethyl Acetate: formic acid $(8: 2: 0.1 \mathrm{v} / \mathrm{v})$ at 510 $\mathrm{nm}$. The accuracy of recovery was checked by triplicate analysis of plant samples spiked with known amount of ursolic acid at three different concentrations. The average amounts of the compound in the whole plant of these species are shown in Table 1. From this table it is clear that the amount of ursolic acid was maximum in $S$. angustifolia $(0.6475 \%)$. Densitometric scans obtained have similar pattern in extracts of the three Swertia species along with biomarker ursolic acid. (Figures 2 and $\mathbf{3}$ ).

Table 1. Results from quantitative analysis of Ursolic acid in different Swertia species.

\begin{tabular}{cc}
\hline Species & Amount of Ursolic acid ${ }^{*}$ [\% dry weight] \\
\hline Swertia angustifolia & 0.6475 \\
Swertia alata & 0.3076 \\
Swertia paniculata & 0.5510 \\
\hline
\end{tabular}

${ }^{*}$ Results are mean from triplicate analysis.

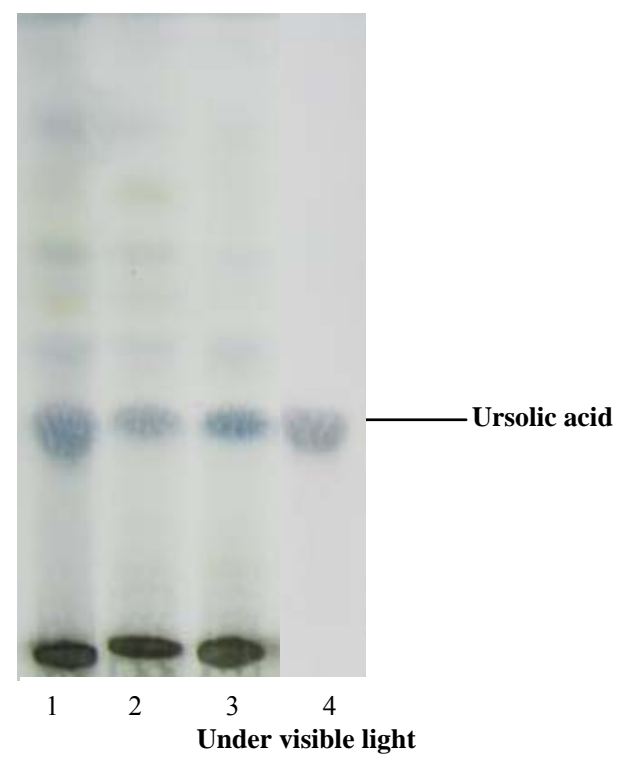

$1=$ Swertia angustifolia $; 2=$ Swertia alata $; 3=$ Swertia paniculata $; 4=$ Standard (ursolic acid).

Figure 2. Estimation of ursolic acid. 


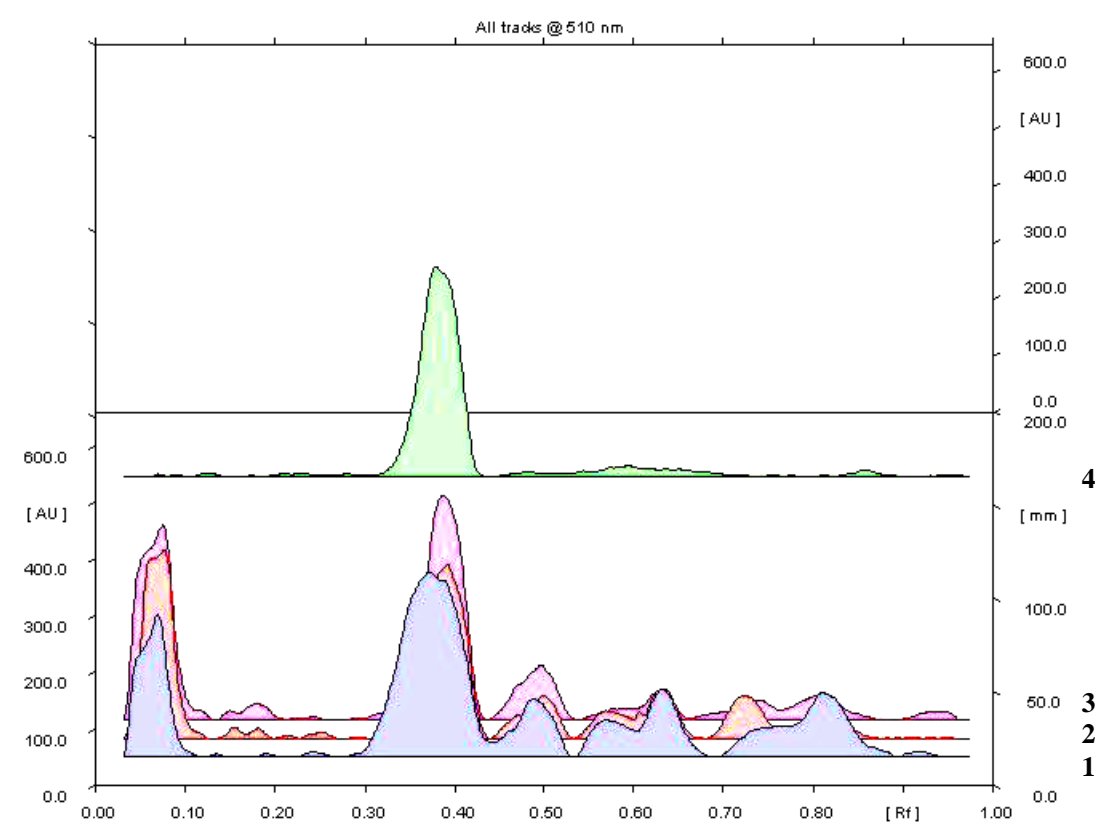

Figure 3. Densitometric scan (at $510 \mathrm{~nm}$ ) profile.

Precision of scanner was also checked by scanning same spots five times and coefficient of variance was calculated. Repeatability of method was also established by applying $3 \mu \mathrm{g}$ per spot of standard solution five times and coefficient of variance was calculated. Limit of detection (LOD) and limit of quantification (LOQ) were also determined. Calibration curve (range $2-10 \mu \mathrm{g}$ ) of ursolic acid was linear (Table 2).

Table 2. Method validation parameters for the estimation of Ursolic acid by HPTLC densitometry in different Swertia species.

\begin{tabular}{cc}
\hline Parameter & Ursolic acid (average values) \\
\hline Recovery (\%) & 97.34 \\
Precision (\% RSD) & \\
CV (instrument precision) & 0.76 \\
CV (method precision) & 1.31 \\
Inter-day precision & 0.68 \\
Intra-day precision & 0.73 \\
Limit of detection & $0.86 \mu \mathrm{g}$ \\
Limit of quantification & $2.62 \mu \mathrm{g}$ \\
Specificity & Specific \\
Correlation coefficient & 0.986 \\
Linearity range & $2-10 \mu \mathrm{g} \cdot \mathrm{spot}^{-1}$ \\
Linear regression coefficient & $\mathrm{y}=4807.861+3224.411$ \\
Slope & $4.010 \pm 0.4694$ \\
Y-Intercept & $8878 \pm 1285$ \\
Robustness & Robust \\
\hline
\end{tabular}

We have done qualitative TLC profiling of all the Swertia species along with a parallel run of Oleanolic and Ursolic acids. In this study we found OA and UA have almost similar $\mathrm{R}_{\mathrm{f}}$ values, however after derivatization with anisaldihide-sufuric acid, bands of UA appears a florescent yellow but OA appears as dark bluish-brown in colour. In the present study we have calculated peak percentage of UA only (Figure 4).

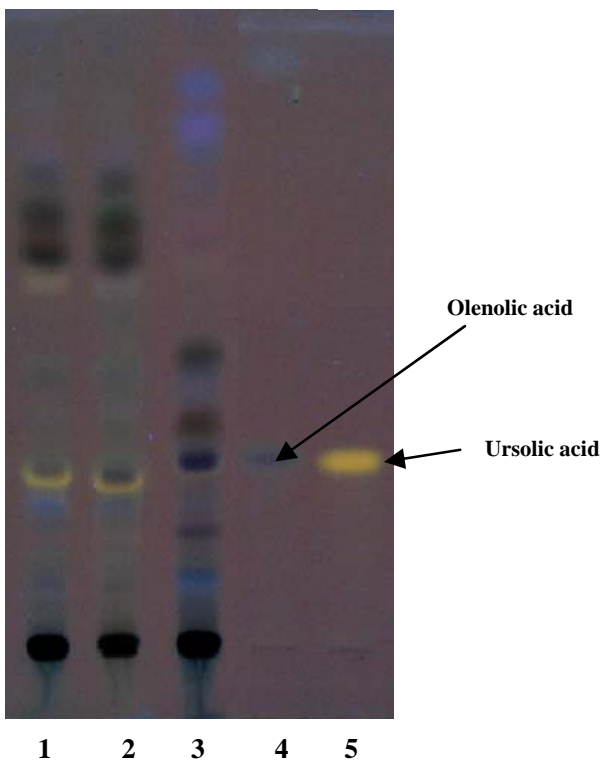

1) Swertia alata; 2) S. angustifolia; 3) S. paniculata; 4) Oleanolic acid (OA); 5) Ursolic acid (UA).

Figure 4. A comparative TLC profile of OA \& UA along with different Swertia species. 


\section{Conclusions}

On the basis of these studies it can be concluded that the method described above for determination of ursolic acid as marker compound in different Swertia species is simple, sensitive, economical, and suitable for rapid screening of many plant samples. The analysis does not require special sample pretreatment and as many as fifteen samples can be analyzed on a single $20 \mathrm{~cm} \times 20 \mathrm{~cm}$ TLC plate. The method can be used for the routine quality control of Swertia species as well as for the quantification of ursolic acid in other plant materials as well as in compound herbal formulations containing ursolic acid.

\section{Acknowledgements}

The authors are grateful to Director, NBRI, for providing all the facilities to conduct this research work and are also thankful to National Medicinal Plant Board, India for financial support.

\section{References}

[1] S. Garg, "International Bioscience Monograph," Today \& Tomorrow's Printers \& Publishers, India, 1987.

[2] Anonymous, "The Wealth of India, a Dictionary of Indian Raw Materials and Industrial Products," Council of Scientific and Industrial Research, New Delhi, 1976, pp. 77-81.

[3] R. N. Chopra, S. L. Nayar and I. C. Chopra, "Glossary of Indian Medicinal Plants," CSIR, New Delhi, 1956, p. 237.

[4] B. D. Naithani, "Flora of Chamoli, Botanical Survey of India,” Botanical survey of India, Calcutta, 1985, p. 433.
[5] U. Dhar and P. Kachroo, "Alpine Flora of Kashmir Himalaya," Scientific Publishers, Jodhpur, 1983, p. 132.

[6] S. P. Ambasta, "The Useful Plants of India," Publication \& Information Directorate, CSIR, New Delhi, 1986, pp. 608-609.

[7] K. S. Khetwal and R. S. Bisht, "A Xanthone Glycoside from Sweria speciosa," Phytochemistry, Vol. 27, No. 6, 1988, pp. 1910-1911. doi:10.1016/0031-9422(88)80481-3

[8] A. K. Chakravarty, S. Mukhophadhyay, K. Masuda and H. Ageta, "More of Swertane Triterpenoids from S. chirayita Buch-Ham," Indian Journal of Chemistry B, Vol. 31, 1992, pp. 70-71.

[9] S. Ghosal, P. V. Sharma, R. K. Chaudhuri and S. K. Bhodtacharya, "Chemical Constituents of the Gentianaceae-V: Tetraoxygenated Xanthones of Sweria chirayita Buch-Ham," Journal of Pharmaceutical Sciences, Vol. 62, No. 6, 1973, pp. 926-930. doi:10.1002/jps.2600620614

[10] A. K. Chakravarty, S. Mukhopadhyay, S. K. Moitra and B. Das, "Syrungareinol, a Hepatoprotective Agent and Other Constituents from Sweria chirayita," Indian Journal of Chemistry B, Vol. 33, 1994, pp. 405-408.

[11] P. K. Chaudhuri and W. M. Daniewshi, "Unambigous Assignments of the $1 \mathrm{H}$ and $13 \mathrm{C}$ Chemical Shifts of the Major Bitter Principles of Sweria chiraita by 2D-NMR Study and Characterization of Other Constituents," Polish Journal of Chemistry, Vol. 69, 1996, pp. 1514-1519.

[12] A. K. Chakravarty, S. Mkhopadhyay and B. Das, "Swertane Terpenoids from Swertia chirayita," Phytochemistry, Vol. 30, 1991, pp. 4092-4087.

[13] V. S. Rana and M. S. M. Rawat, "A New Xantone Glycoside and Antioxidant Constituents from the Rhizomes of Sweria speciosa," Chemistry and Biodiversity, Vol. 2, No. 10, 2005, pp. 1310-1315. doi:10.1002/cbdv.200590102 